\title{
Sublime, sublimação e expressão: a ressonância de Kant e Freud na articulação adorniana entre arte e sociedade
}

Fernanda Proença

Doutoranda EM FILOSOFIA PELA UFMG

O burguês deseja que a arte seja voluptuosa e a vida ascética; o contrário seria melhor. Theodor W. Adorno. ${ }^{\mathrm{I}}$

\section{Do caráter emancipatório da arte}

Em Minima moralia, a crítica que Adorno apresenta a Freud é frontal, dizendo claramente, na abertura do aforismo 136: "Artistas não sublimam”. ${ }^{2}$ Ainda que tal frase componha uma ampla análise realizada por Adorno nessa obra, interessa-nos aqui aquelas implicaçóes que perpassam as relaçóes entre arte e sociedade. Lembremos de início que, segundo Freud, a sublimação seria o motor para criação artística, tratando-se de um movimento de elaboração inerente à

'ADORNO, Theodor W. Teoria estética. Tradução de Artur Morão. Lisboa, Edições 70, 2016, p. 29.

${ }^{2}$ ADORNO, Theodor W. Minima moralia. Tradução de Artur Morão. Lisboa, Edições 70, 1993, p. 186 
economia pulsional dos artistas. A energia potencialmente desagregadora característica das pulsóes seria canalizada, afastando-se de seu teor intrinsecamente sexual e desviando sua realização para a produção das obras de arte. Assim, o ponto de partida da crítica que Adorno apresenta na Minima moralia dá-se, então, em torno dessa premissa da aceitabilidade social da obra de arte, a seu ver, implícita na sublimação freudiana. Para ele, a adequação ao socialmente desejável torna-se essencial para que a obra de arte seja o vetor de realização das pulsões conforme proposto por Freud, uma vez que a realização direta (não sublimada) das mesmas é rechaçada pelo sujeito justamente em virtude de seu teor sexual incompatível com o princípio de realidade, ou seja, não-realizável no contexto social habitado pelo artista. Essa caracterização adorniana encontra respaldo em passagens dos textos de Freud desde a primeira utilização do termo, em uma carta de 1897 a Fliess, na qual, ainda que não designe propriamente um conceito psicanalítico, Freud recorre ao termo para referir-se a fantasias trazidas à análise pelas histéricas, descrevendo-as como "estruturas protetoras, sublimaçôes dos fatos, embelezamento deles". ${ }^{3}$ Nos textos que se seguem, Freud oferece uma via que permite a Adorno adensar sua interpretação da sublimação como mecanismo civilizatório, ou seja, de adequação do sujeito à sociedade, em consonância com a cultura. ${ }^{4}$ Em outras palavras, a sublimação seria a alternativa mais interessante disponível aos sujeitos frente às exigências civilizatórias de supressão das pulsões e constitutivas da cultura em seu sentido mais aproximado de um princípio de realidade opressor. Já no caso Dora, de 1905, Freud descreve o mecanismo de sublimação como ferramenta para "garantir um grande número de realizações culturais” e, posteriormente, aponta como o processo de sublimação pulsional seria capaz de "colocar à disposição da atividade civilizada uma extraordinária

${ }^{3}$ FREUD, Sigmund. A correspondência completa de Sigmund Freud para Wilhelm Fliess 1887-1904. Tradução de Vera Ribeiro. Rio de Janeiro, Imago, 1986, p. 342

${ }^{4}$ Importante pontuar como o termo "cultura", nesse contexto, pretende-se alinhado ao cultivo de uma conduta polida, agregadora, de diluição das vicissitudes do sujeito (encarnadas pelas pulsóes) em prol de uma pasteurização dos comportamentos de acordo com aquilo que, como sociedade, julgamos adequado.

${ }_{5}^{5}$ FREUD, Sigmund. "Fragmentos da análise de um caso de histeria”. In: ESB. v. VII. Rio de Janeiro, Imago, 1969b, pp. 53-54. 
quantidade de energia", ${ }^{6}$ consolidando-se como via principal de constituição da cultura (Cf. GARCIA, 1998). Esse viés interpretativo encontra ainda mais respaldo na obra, ${ }^{7}$ de 1930, no qual Freud indicará a sublimação como "traço especialmente destacado do desenvolvimento cultural; ela possibilita que atividades psíquicas superiores - científicas, artísticas e ideológicas - representem um papel tão significativo na vida cultural"'.

Em Minima moralia, é esse o ponto chave de discordância de Adorno com a teoria freudiana, uma vez que a estética adorniana tem como um de seus pilares não o apaziguamento, mas a dissonância estabelecida pela arte com relação ao seu entorno, a potência emancipatória resguardada em sua alteridade. Neste sentido, Adorno pontua:

Crer que eles [os artistas] não satisfazem nem reprimem seus desejos, mas transformam-nos em realizações socialmente desejáveis, é uma ilusão psicanalítica; aliás, nos dias de hoje, obras de arte legítimas são, sem exceção, socialmente indesejadas. ${ }^{9}$

Adorno tem em mente, nessa passagem, os novos paradigmas que a arte do início do século XX estabeleceu especialmente através das vanguardas ${ }^{\mathrm{IO}}$ que, em sua agressividade, aproximam-se mais de um regime de colisão do que de sublimação. Posteriormente, na Teoria estética, Adorno dirá:

${ }^{6}$ FREUD, Sigmund. "Fantasias histéricas e sua relação com a bissexualidade". In: ESB. v. IX. Rio de Janeiro: Imago, 1969, p. 8o.

${ }^{7}$ Cf. GARCIA, Claudia Amorim. "Sublimação e cultura de consumo". In: RABELLO

DE CASTRO, Lucia. (Org.) Infância e adolescência na cultura do consumo. Rio de Janeiro, NAU, 1998.

${ }^{8}$ FREUD, Sigmund, $O$ mal-estar na cultura. Tradução de Renato Zwick. Porto Alegre, L\&PM, 2OIO, p. IOI

9 ADORNO, Theodor W. Minima moralia. Tradução de Artur Morão. Lisboa, Edições 70, 1993, p. 186.

${ }^{\text {Io }}$ Refiro-me aqui especialmente às vanguardas ditas "líricas", ou "pulsionais", como o surrealismo e o dadaísmo, que promoviam uma estetização do real que "resultaria da crítica à mercadoria, feita fetiche". (Cf. FABBRINI, Ricardo. "O fim das vanguardas". In: Cadernos da pós-graduação. Instituto de Arte/Unicamp, ano 8, n. 2, 2006, p. III). 
À aceitação conformista da concepção corrente da obra de arte como bem cultural agradável, levada a cabo pela psicanálise, corresponde um hedonismo estético que expulsa da arte toda negatividade para os conflitos pulsionais da sua gênese, silenciando os resultados. Se da sublimação e da integração conseguidas se fizer o Uno e o Todo da obra de arte, esta perde a força pela qual ultrapassa o existente. ${ }^{\text {II }}$

É possível que Adorno, no texto de 1968, tenha absorvido a leitura de Marcuse, segundo a qual é necessário diferenciar o princípio de desempenho, típico do capitalismo, do princípio de realidade. ${ }^{\mathrm{I2}}$ Ainda que o princípio de realidade seja algo de inalienável na experiência do sujeito, sua formatação é contingente, passível de transformação; em virtude de seu caráter histórico, o princípio de realidade em sua substancialidade (conteúdo) não figura como algo de necessário e imutável. Assim, se assumimos a realidade como algo passível de transformação, a arte figura nesta como elemento conflitante. Essa visão difere do apaziguamento implícito no processo sublimatório - que, ainda que não exclua propriamente a possibilidade de uma obra apresentar-se como dissonante dos cânones tradicionais, não escapa à expectativa subjacente de conformidade com a realidade; apaziguamento este essencial para Freud, pois apenas ele justificaria o desvio da pulsão, conforme exemplificada nesta passagem do texto "O poeta e o fantasiar":

O poeta suaviza o caráter de seus devaneios egoístas por meio de alterações e disfarces, e nos suborna com o prazer puramente formal, isto é, estético, que nos oferece na apresentação de suas fantasias. Denominamos de prêmio de estímulo ou de prazer preliminar ao prazer desse gênero, que nos é oferecido para possibilitar a liberação de um prazer ainda maior, proveniente de fontes psíquicas mais profundas. $^{\text {I3 }}$

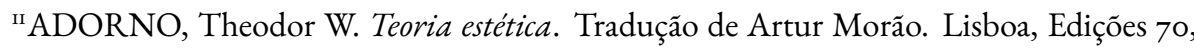
2016, p. 28.

I2 "Os vários modos de dominação (do homem e da natureza) resultam em várias formas históricas do princípio de realidade.” (MARCUSE, Herbert. Eros e civilização. Uma interpretação filosófica do pensamento de Freud. Tradução de Álvaro Cabral. Rio de Janeiro, Zahar, 1975, p. 5I).

${ }^{13}$ FREUD, Sigmund. "Escritores criativos e devaneios". Tradução de Maria Aparecida Moraes Rego. In: ESB. v. IX. Rio de Janeiro, Imago, 2006, p. I42. 
Notemos que Freud, na referida passagem, toma o ponto de vista do observador, que encontraria prazer na fruição da obra em decorrência do processo de sublimação liderado pelo artista, de forma que a pacificação das pulsões funcionaria em mão dupla. Em outras palavras, da mesma maneira que a feitura do objeto concretiza um desvio da realização de pulsões do artista, também o observador realiza algo da ordem do apaziguamento psíquico através da experiência de prazer oferecida pelo contato com a obra, estendendo o processo de adequação social da produção para a recepção e, assim, duplicando os pontos de entrada para a crítica adorniana: decorre do prazer experimentado, em ambos os casos, uma sensação de reconciliação com o mundo. A competência do objeto artístico para, através da beleza, restaurar a crença na coerência da natureza - essa ilusão de conformidade entre o sujeito e o mundo que ele habita - nos remete à terceira crítica kantiana. Nela, a representação do belo, através do juízo reflexionante, é o elo que permite a Kant atribuir coerência à natureza, em contiguidade com o sujeito: "Podemos considerar a beleza natural como exibição do conceito de idoneidade formal (meramente subjetiva) e os fins da natureza como exibição do conceito de uma idoneidade real (objetiva), julgando a primeira idoneidade com o gosto (esteticamente, mediante o sentimento de agrado) e a segunda com o entendimento e a razão (logicamente, por meio de conceitos)" ${ }^{14}$ Neste sentido, o sentimento do belo em Kant trata também da reconciliação, gerando prazer através da percepção da idoneidade da natureza expressa em harmonia, no prazer do livre jogo entre imaginação e entendimento, que, por sua vez, percebe consonâncias e não divergências.

No que tange ao belo artístico, sugiro que esse sentimento de reconciliação está aparentado à mímesis, pois a verossimilhança da arte representativa oferece-se justamente à contemplação da conformidade, insuflada pela valoração histórica da capacidade de subsumir o mundo à esfera da ação humana. "O que o espírito promete é o lugar do momento sensível na arte, não a satisfação do contemplador. - O romantismo queria simplesmente equiparar o que surge na apparition ao elemento artístico." " ${ }^{\text {Is }}$ Em outras palavras, a arte mimética privilegia um sentimento

${ }^{14}$ KANT, Immanuel. Crítica da faculdade de julgar. Tradução de Daniela Botelho B. Guedes. São Paulo, Ícone, 2009, p. 38.

${ }^{15}$ ADORNO, Theodor W. Teoria estética. Tradução de Artur Morão. Lisboa, Edições 70, 2016, p. I3I. 
de prazer oriundo da familiaridade, que tem um caráter afirmativo enquanto estandarte da primazia da técnica. ${ }^{16} \mathrm{~A}$ questão dilata-se quando a arte moderna a coloca em discussão, operando, em sua não-subserviência à realidade, uma passagem da representação à expressão como resposta a esse conflito histórico. $\mathrm{Na}$ sua tomada de autonomia e movimento autorreflexivo, privilegia a expressão como forma de afastar-se da proposta contemplativa em prol de uma projeção racionalimaginativa para além do construto. Conforme lemos em Minima moralia: "A modernidade é uma categoria qualitativa, e não cronológica. Do mesmo modo que ela não se deixa reduzir à forma abstrata, a ela é necessário recusar as conexões superficiais convencionais, a aparência da harmonia, a ordem corroborada pela mera cópia." ${ }^{17}$ Podemos ler essa passagem como um afastamento de Adorno de algumas premissas atribuíveis ao belo kantiano. Se o modelo representativo da mímesis, em sua ilusão de harmonia, privilegia uma postura contemplativa do observador, torna-se inadequado à postura crítica inerente à nova arte. Ainda, se a obra de arte moderna exige uma postura quase combativa do observador, parece-me que o prazer desinteressado dá lugar ao desprazer denunciador da incompatibilidade das faculdades cognitivas com a arte, aproximando-se daquilo que Kant descreveu como sublime.

A experiência do sublime pode ser descrita como abalo, comoção. ${ }^{18}$ Nisso, ela revela uma dupla violência: a razão violenta a imaginação, forçando-a a representar o irrepresentável (suprassensível) enquanto a imaginação violenta a sensibilidade, dada a atração e repulsão dos objetos que despertam o sublime. Essa relação de agressão entre razão e sensibilidade parece muito mais aparentada à arte moderna do que a mera contemplação do dado sensível. O colapso do primado da representação liberta a imaginação do acordo - disciplinar - subjetivo

${ }^{16}$ Para efeitos de argumentação, aqui entendemos por "arte mimética” as obras que repousam na verossimilhança, na cópia do real como objetivo final de sua feitura. No entanto, é importante salientar que Adorno percebe uma dimensão mimética em toda obra de arte, inalienável de sua realidade empírica.

${ }^{17}$ ADORNO, Theodor W. Minima moralia. Tradução de Artur Morão. Lisboa, Edições 70, I993, p. I9I.

${ }^{18}$ Sobre o contraponto entre contemplação e abalo em Kant, ver: BARRETO, Marco. "A imaginação e o sublime - herança de um pavor: de Kant a Bachelard”. In: DUARTE, Rodrigo (Org.) Belo, sublime e Kant. Belo Horizonte: UFMG, 1998, pp. I73-I8I. 
com o entendimento. Tal interpretação encontra respaldo no pensamento de Lebrun:

O sentimento do belo outorgava ainda "à coisa e à natureza mesmas" suficiente presença para que o sujeito estético tivesse o direito de imputar-lhe a finalidade subjetiva que ele sentia: um sujeito encontrava o sentimento de reencontrar uma natureza magicamente acolhedora. Com o sublime, essa relação cessa. ${ }^{19}$

O sublime kantiano engendra uma autocrítica da imaginação, pois percebe a irrepresentabilidade das ideias de infinito, liberdade, totalidade. Assim, diferentemente do belo, o sublime refere-se ao suprassensível, às ideias da razão descoladas da forma e, dessa maneira, lança-se para além do construto. "Na experiência do sublime o espírito é incitado a abandonar a sensibilidade. A razão violenta a imaginação, alargando-a, obrigando-a a exprimir o informe da natureza” ${ }^{\text {2o. }}$. É dessa superação momentânea da determinação natural (empírica, objetiva) pelo espírito que o sujeito experimenta uma "vitória momentânea do ideal sobre o natural" Entendo que é nesse ponto, no embate entre real e ideal, que a expressão adorniana encontra eco, pois ela privilegia justamente a alteridade do objeto artístico e sua capacidade de estimular a imaginação no sentido de oferecer um vislumbre utópico emancipatório. Enquanto o belo aproxima-se de uma idealidade reconciliatória, percipiente da conformidade a fins da natureza, o sublime move-se na arena do conflito, denunciador das insuficiências do entendimento frente à natureza. $\mathrm{Da}$ mesma forma, na arte não representativa a inadequação entre as expectativas da razão e a imanência do construto funciona como combustível para a expressão alçar-se àquilo que escapa ao dado imediato, através dos esforços da imaginação. No entanto, Adorno pontuará, de forma algo aparentada à sua crítica ao princípio

${ }^{19}$ LEBRUN, Gérard. Kant e o fim da metafísica. Tradução de Carlos Alberto Ribeiro de Moura. São Paulo, Martins Fontes, 2002, p. 588.

${ }^{2}$ BARRETO, Marco. "A imaginação e o sublime - herança de um pavor: de Kant a Bachelard”. In: DUARTE, Rodrigo (Org.) Belo, sublime e Kant. Belo Horizonte: UFMG, 1998, pp. I73-I8I; p. I74.

${ }^{21}$ GARCIA-MORENTE, Manuel. 1975, p. I86. Apud BARRETO, Marco, op. cit., 2008, p. 174 . 
de realidade da psicanálise, que falta à experiência estética kantiana a percepção de sua historicidade implícita. Para ele, como o prazer oriundo da experiência estética traz relação com a intuição de uma coerência da natureza, a própria ideia de natureza precisa ser tratada como um conceito em devir. Se a natureza kantiana equivale ao mundo do qual a obra de arte se destaca, a natureza em questão para Adorno é o mundo da técnica, que difere daquela por sua artificialidade (uma natureza à segunda potência, pois criada pelo ser humano), contingência (pode e deve ser modificada através da desconstrução dos mecanismos de dominação) e incoerência (não resguarda uma expectativa ou intuição de racionalidade interna). Assim, a natureza "pura" kantiana é considerada insuficiente por Adorno, que percebe nessa aproximação, nessa crença na possibilidade de um retorno a algo de originário, uma certa ingenuidade do gênio. Porém, aceita essa correção, é ainda possível identificarmos o juízo estético kantiano com o caráter emancipatório da estética adorniana, no sentido de ambos atribuírem uma dimensão de liberdade à natureza: enquanto em Kant a imaginação é o elo que permite que os espaços de necessidade e liberdade se entremeiem, ${ }^{22}$ em Adorno é também ela que resguarda a esperança da liberdade frente à dominação.

A expressão entra em pauta também no debate com a psicanálise, quando Adorno propóe, ainda em Minima moralia, que seria esse o conceito adequado à compreensão tanto da dinâmica subjetiva do artista na produção da obra quanto na recepção da mesma. ${ }^{23} \mathrm{O}$ que a expressão tem em comum com a sublimação é o fato de serem ambas uma resposta ao princípio de realidade, impeditivo da realização da pulsão à qual está vedada a comunicação com o objeto. No entanto, a expressão prevê uma externação imagética do conflito, uma objetividade sensível que carrega sua força desestabilizadora, e nisso difere da sublimação.

22 "This idea (...) serves as the sought-after 'bridge' between the theoretical and the practical, spanning the gulf previously created between the knowledge of objects according to the conditions of possible experience and the realization of freedom under the unconditional of moral law.” LYOTARD, Jean-François. Lessons on the analytic of the sublime. Transl. Elizabeth Rottenberg. Stanford, Stanford University Press, 2004., p. I.

${ }^{23} \mathrm{Na}$ Teoria estética, o conceito de expressão figura como polo do par dialético estabelecido com o conceito de construção. Nele encontra-se a tensão que perfaz o núcleo da obra, articulando, de um lado, o pulsional, afetivo, ebulitivo (referentes à expressão) e, do outro, o métier, saber fazer, planejamento (referentes à construção). 
A expressão nega a realidade ao contrapor-lhe o que não se iguala a esta, mas não a renega; ela encara nos olhos o conflito, que resulta cegamente no sintoma. O que a expressão tem em comum com a repressão é que nela a emoção se encontra bloqueada pela realidade. (...) Ela substitui seu objetivo, assim como sua própria "elaboração" pela censura subjetiva, por uma elaboração objetiva: sua revelação polêmica. Isso a distingue da sublimação: toda expressão bem-sucedida do sujeito é, por assim dizer, um pequeno triunfo sobre o jogo de forças de sua própria psicologia. O páthos da arte está ligado ao fato de que ela, precisamente por retirar-se todavia à acomodação, sem dar prosseguimento à violência do exterior na deformação do interior. ${ }^{24}$

O desenvolvimento dessa avaliação adorniana sobre a sublimação em Freud encontra novos contornos na Teoria estética. Mantendo ainda sua posição em favor da expressão como viés preferível à sublimação psicanalítica para o trato com a arte moderna, Adorno desdobra essa problemática para encontrar, então, a questão de tomarmos a obra como projeção do quadro psicanalítico do artista, como externação psicossomática de patologias. ${ }^{25}$ Adorno dirá claramente: "Quem compreende as obras de arte pela imanência da consciência nelas, não as compreende verdadeiramente. ${ }^{{ }^{2} 6} \mathrm{~A}$ crítica adorniana a essa abordagem tem seu cerne na irrelevância do construto sustentada por ela, nas limitaçốes impostas à estética se esta for reduzida a um diagnóstico empírico das inadequaçóes subjetivas ao princípio de realidade ${ }^{27}$ Caminhando por essa via, tal abordagem implicaria

${ }^{24}$ ADORNO, Theodor W. Minima moralia. Tradução de Artur Morão. Lisboa, Edições 70, 1993, p. 187.

${ }^{25}$ Um exemplo clássico dessa abordagem encontra-se no texto de Freud Uma recordação de infância de Leonardo da Vinci, de I9Io, sobre o qual Ana Maria Loffredo comenta: "Freud havia dito que, entre os caminhos seguidos pela curiosidade infantil, Leonardo teria conseguido se esquivar do caminho da neurose e se embrenhado nas trilhas da sublimação desde o início”. (LOFFREDO, Ana Maria. Figuras da sublimação na metapsicologia freudiana. São Paulo, Escuta/Fapesp, 20I4, p. 69.)

${ }^{26}$ ADORNO, Theodor W. Teoria estética. Tradução de Artur Morão. Lisboa, Edições 7o, 2016, p. 188.

${ }^{27}$ Cf. DUARTE, Rodrigo. "Sublimação ou expressão: um debate sobre arte e psicanálise a partir de T. W. Adorno”. In: Revista brasileira de psicanálise, v. 32 (2), 1998, pp. 319-335; 33I. 
na aceitação de que qualquer realização sensível do estado psicanalítico do artista cumpriria os requisitos para ser considerado obra de arte, tornando irrelevante (ou mesmo irrealizável) uma pretensa graduação qualitativa da produção artística, algo impensável para Adorno, que pontua amplamente nas suas reflexôes estéticas o papel central do teor de verdade das obras de arte autênticas que as separa das mercadorias culturais - diferença esta que é o fiel da balança entre estar à serviço de um esquema de dominação socioeconômico ou ser a potencialidade última na sua desarticulação.

Enquanto fundador da psicanálise, parece natural que Freud tenha direcionado suas investigações aos processos psíquicos dos indivíduos em detrimento da análise de obras de arte enquanto objetos da estética. Freud o dirá claramente em "O poeta e o fantasiar", ao esclarecer seu objeto de estudo na relação entre o devaneio e a produção artística:

Vamos analisar esses [poetas], e, para nossos fins, não escolheremos os mais aplaudidos pelos críticos, mas os menos pretensiosos autores de novelas, romances e contos que gozam, entretanto, da estima de um grande número de leitores. ${ }^{28}$

O que interessa a Freud é a maneira como o devaneio se materializa em obra de arte, sendo a qualidade estética dessa realização irrelevante. Ou, mais do que isso, as obras de ampla aceitação popular seriam melhores exemplos do processo de sublimação, por sua estrutura palatável que propicia ao leitor a experiência de identificação, de reconhecer-se ali na afinidade com suas "histórias egocêntricas". $\mathrm{Na}$ Teoria estética, Adorno esclarece que, se a arte teve um momento no qual a sublimação fazia sentido, este era pautado na identificação do observador com a obra, não o contrário, conforme ocorre no mundo administrado:

A antiga afinidade de contemplador-contemplado é invertida. Ao reduzir a obra de arte a simples factum, gesto típico do comportamento de hoje, vende-se também em saldo o momento mimético,

${ }^{28}$ FREUD, Sigmund. "Escritores criativos e devaneios". Tradução de Maria Aparecida Moraes Rego. In: ESB. v. IX. Rio de Janeiro, Imago, 2006, p. I39. 
incompatível com toda a essência coisal. O consumidor pode à vontade projetar as suas emoções, os seus resquícios miméticos, no que lhe é apresentado. ${ }^{29}$

\section{Do caráter histórico-social da arte}

É curioso notar como o enfoque freudiano alcança algo muito similar à estética kantiana no que tange à aproximação da obra de arte como objeto de manifestação de instâncias intrínsecas ao sujeito, à revelia da imanência do objeto, tão cara a Adorno. Ambas as aproximaçóes não atentam para aquilo que a obra apresenta em sua dimensão sensível, de suas características formais pormenorizadas, reduzindo o universal inerente às obras de arte a algo da ordem do sujeito transcendental, no caso de Kant, ou da ordem da similitude da economia psíquica dos indivíduos, no caso de Freud. Para Adorno, a dificuldade que essa primazia do sujeito (abstrato) frente ao construto apresenta é que ela propicia que a arte seja cooptada pela indústria cultural. Como já vimos, a mímesis opóe-se à expressão que Adorno defende, pois esta se pauta na alteridade, encarando a realidade na qual se insere como negatividade à qual, ao mesmo tempo, se contrapõe. Desdobrando essa premissa no sentido de abarcar o debate sobre finalidade sem fim que Kant atribui à experiência estética, Adorno coloca:

Toda obra de arte possui uma contradição insolúvel naquela "finalidade sem fim", pela qual Kant definia o estético; no fato de que ela representa uma apoteose do fazer, da capacidade de dominar a natureza, que, enquanto criação de uma segunda natureza, se põe como absoluta, sem fim e existindo em si mesma. ${ }^{30}$

$\mathrm{Na}$ Dialética do esclarecimento, juntamente com Horkheimer, Adorno já pontuava como a indústria cultural toma o lugar do esquematismo kantiano ao usurpar ao sujeito a capacidade de ajuizamento.

${ }^{29}$ ADORNO, Theodor W. Teoria estética. Tradução de Artur Morão. Lisboa, Edições 7o, 2016, p. 34 .

$3^{\circ}$ ADORNO, Theodor W. Dialética negativa. Tradução de Marco Antônio Casanova. Rio de Janeiro, Jorge Zahar, 2009, p. 198. 
$\mathrm{Na}$ alma devia atuar um mecanismo secreto destinado a preparar os dados imediatos de modo a se ajustarem ao sistema da razão pura. Mas o segredo está hoje decifrado. (...) Para o consumidor, não há nada mais a classificar que não tenha sido antecipado no esquematismo da produção. ${ }^{31}$

O esquematismo transcendental, antes realizado pelo sujeito, é diluído em um sistema dentro do qual fenômenos se apresentam já conceitualizados, enquanto os conceitos já vêm ilustrados. Ou seja, a potencialidade do sujeito transcendental, que a crítica kantiana tem como alicerce da possibilidade da experiência estética, encontra-se em certa medida substituída pela indústria cultural, uma vez que esta atua na produção dos desejos da massa, oferecendo, em seguida, as mercadorias culturais para realização desses mesmos desejos inautênticos; um "idealismo sonhador" caricatural, manifesto nas mercadorias culturais enquanto "arte sem sonho". ${ }^{32}$ Interessante que Adorno traga nessa passagem o sonho como algo que escapa à indústria cultural, o que nos remete novamente a Freud. Se o sonho próximo ao devaneio pela identificação de ambos com processos sublimatórios - é o que falta à mercadoria cultural e aquilo que a diferencia da obra de arte autêntica, então fica resguardado o potencial subversivo do sonho. É este um dos pontos nos quais Adorno apoia-se em Freud: ainda que a sublimação não dê conta da experiência estética como um todo, ela figura como elemento constitutivo essencial da relação com a arte por ser oriunda de uma não subserviência à realidade, trincheira dos desejos do indivíduo que fazem dele único e potencialmente transformador do mundo extrassubjetivo. Quando essa competência é instrumentalizada pela indústria, o que temos é um processo de reificação da promesse de bonheur da arte:

Desde o começo do filme já se sabe como ele termina, quem é recompensado, e, ao escutar música ligeira, o ouvido treinado é perfeitamente capaz, desde os primeiros compassos, de adivinhar o

${ }^{3}$ ADORNO, Theodor W.; HORKHEIMER, Max. Dialética do esclarecimento. Tradução de Guido Antonio de Almeida. Rio de Janeiro, Zahar, 2006, p. Io3.

${ }^{32}$ Id. 
desenvolvimento do tema e sente-se feliz quando ele tem lugar como previsto. ${ }^{33}$

Assim, a indústria cultural priva o sujeito de seu protagonismo no devanear ao tomar o lugar de sua imaginação na construção do desejo.

A mercadoria cultural, no que se refere ao desejo, conflita com a sublimação freudiana, pois subverte o princípio de prazer de que ela deriva; concomitantemente, conflita, por esse mesmo viés do desejo, com a estética kantiana, atribuindo a objetos pretensamente artísticos uma finalidade. Quando a esfera da cultura está para a sociedade como simulacro domador de consciências, ela torna-se peça na engrenagem do mundo administrado, com a finalidade última de exercer dominação em nome do lucro. No entanto, essa finalidade é articulada justamente sobre o prazer, em uma satisfação pretensamente desinteressada. É porque o observador percebe a mercadoria cultural como arte desinteressada que ele não atenta para sua potência de dominação, o que a torna mais perversa. É a isso que Adorno se refere quando diz que o sujeito transcendental kantiano teria sido substituído por uma universalidade dos juízos na modernidade: "porque todos, sem conflito, perseguem o interesse particular, este aparece, por sua vez, precisamente como universal e, por assim dizer, desinteressado". ${ }^{34}$ A versão de universalidade considerada legitima por Adorno vai por outro caminho: fundamenta-se na possibilidade de encararmos a obra como elemento cristalizador de sedimentaçóes sócio-históricas que, por seu caráter compartilhado, alcançam na experiência do sujeito algo da ordem do coletivo. Esse ponto é crucial, pois adiciona uma dimensão histórica à universalidade, abarca seu caráter circunstancial e determina, para além do esquematismo kantiano ou da economia psíquica freudiana, uma universalidade pautada na cultura, externada. Adorno dirá que "não pode haver imagem sem imaginário"; 35 esse imaginário é o léxico que dá voz aos elementos formais e estabelece essa relação com o observador. Ao entrar em contato com uma obra de arte, o sujeito é convidado a elaborar algo que o supera enquanto

${ }^{33} \mathrm{Id}$.

${ }^{34}$ ADORNO, Theodor W. Minima moralia. Tradução de Artur Morão. Lisboa, Edições 70, 1993, p. 138 .

${ }^{35}$ ADORNO, Theodor W. Minima moralia. Tradução de Artur Morão. Lisboa, Edições 70, 1993, p. 136. 
indivíduo, que o insere em um diálogo, senão universal, pelo menos referente a um grupo maior que si. Dizer que a obra de arte tem a potência de resgatar esse universal, ainda que se trate aqui de um universal em termos, temporalizado e recortado geográfica e culturalmente, e não um universal necessário e absoluto, é a via de escape de uma relação com a obra reduzida ao solipsismo - um trato ingênuo com a arte que muito se aproxima de uma caricatura da fruição romântica, baseado na catarse e consequente apaziguamento da consciência do sujeito através do processo identificatório de suas determinações individuais na obra.

Notemos, entretanto, que para que seja possível trabalharmos com uma universalidade construída culturalmente é indispensável que haja conhecimento (crítico) da história e da sociedade. Ainda, se a arte desenvolve também uma conversa consigo mesma, especialmente após a perda de sua evidência, ${ }^{36}$ exige-se também um conhecimento da própria história da arte para que se possa participar desse universal/coletivo com a qual ela dialoga na dimensão intraestética. Esse trato não-ingênuo com a arte exige esforço por parte do observador - especialmente na fruição de obras de arte modernas e contemporâneas, por sua tendência à desartificação. Desartificação esta que, por sua vez, é também uma resposta da arte à relação contemplativa que a indústria cultural aprendeu a explorar, uma estratégia para tornar a arte menos consumível. Nas palavras de Adorno:

Mas isso [a arte] se torna difícil para eles [o público] por causa do esforço que é requerido deles pelo ato de receber. Embevecidos com a técnica, transferem seu ódio ao esforço desnecessário de sua existência para o dispêndio de energia que o prazer - enquanto uma dimensão que lhes é essencial - necessita até mesmo em todas as sublimações. ${ }^{37}$

${ }^{36}$ Cf. ADORNO, Theodor W. Minima moralia. Tradução de Artur Morão. Lisboa, Edições 70, 1993, p. II.

${ }^{37}$ ADORNO, Theodor W. Minima moralia. Tradução de Artur Morão. Lisboa, Ediçóes 70, 1993, p. 190. 
Assim, na estética adorniana a relação do observador com a obra é, em certo sentido, mediada, dependente de algo da ordem do conhecimento e que escapa à empiria..$^{8}$

Até aqui, procurei destacar o viés histórico que a estética adorniana atribui aos conceitos, especialmente o conceito de "universal" - o que se encontra em acordo com a fundamentação epistemológica da dialética negativa, que a embasa. No entanto, sendo a questão bastante complexa, seria reducionista traçar uma linha divisória, a partir desse conceito, separando Adorno de Kant e Freud. Uma análise mais pormenorizada permite sugerir que o elemento mediador da experiência estética adorniana sobre o qual o universal é articulado, pode encontrar paralelos no sublime kantiano e na sublimação freudiana, naquilo que trazem também de mediado. Primeiramente, quanto ao sublime kantiano, pode-se argumentar que ele traz em si um apelo extraestético que incorpora essa mediatidade adorniana, pois o sublime é um predicado que, por superar a representação em direção ao irrepresentável, pertence menos às coisas que o belo. A experiência do sublime logra superar o estado de terror inicialmente instaurado, o que só é possível com o auxílio das ideias morais, por sua capacidade de transformar o terror em prazer negativo. Na terceira crítica, Kant coloca essa questão da seguinte maneira: "na verdade aquilo que nós, preparados pela cultura, chamamos sublime, sem desenvolvimento de ideias morais apresentar-se-á ao homem inculto simplesmente de modo terrificante" ${ }^{39}$ Neste sentido, podemos caracterizar o sublime kantiano como adornianamente não-ingênuo, leitura que se fortalece quando notamos que o sublime consegue também escapar ao positivismo típico da Aufklärung, encarnado na representatividade, justamente por sua inerente

${ }^{38}$ Notemos que Adorno não realizará um mero elogio ao homem culto e à cultura, por compreender as implicações dessa caracterização nos processos civilizatórios de dominação. Porém, é impossível escapar a certo elogio à erudição em Adorno, ainda que ele não o faça diretamente, mas negativamente, quando se manifesta contra o filisteísmo e a ignorância. De todo modo, o que procuro destacar é que a recepção da obra ocorre a partir de uma disrupção da forma na direção de uma elaboração crítica da realidade, que só seria possível quando o sujeito encontra-se em posse de elementos para tal. Sugiro que o conhecimento, nesse sentido, estaria idealmente a serviço da crítica, capaz de perceber e questionar as forças dialéticas evidenciadas de forma imanente na obra.

${ }^{39}$ KANT, Immanuel. Crítica da faculdade de juizo. Tradução de Valério Rohden; Antonio Marques. Rio de Janeiro, Forense Universitária, 20I2, p. II4. 
disrupção da forma. Em decorrência disso, no lugar de estimular uma intuição da idoneidade da natureza, como faz o belo, o sublime inspira um encontro da razão com seus próprios limites, que nos permite sentir em nós uma finalidade não expressa na natureza. ${ }^{40}$ É esse deslocamento que consegue, em um só movimento, privilegiar a imaginação (e denunciar os limites da razão) - em consonância com o caráter emancipatório do conceito de expressão adorniano -, e afastar-se do sentimento de idoneidade (necessidade) da natureza - no que se aproxima, então, do conceito adorniano de natureza em devir, passível de transformação, ou seja, do caráter emancipatório da arte. Ainda, para retomar rapidamente a questão supracitada da desartificação, parece viável traçar mais um paralelo entre esta e o sublime, conforme expresso na passagem em que Kant nos diz:

[no sublime] o espírito se sente movido, por oposição ao juízo estético sobre o belo, que é contemplação quieta. (...) é uma comoção, isto é, uma rápida alternância de repulsão e atração do mesmo objeto. ${ }^{41}$

Com esses elementos, gostaria de sugerir que a estética do sublime kantiano consegue, talvez à revelia das intençôes do autor, resguardar um espaço para a arte não representativa ${ }^{42} \mathrm{e}$, consequentemente, oferecer ferramentas para pensarmos a arte moderna e contemporânea. ${ }^{43}$

Passemos então à análise da sublimação freudiana, procurando investigar seu caráter mediado e as projeções históricas que Adorno lhe atribui. Daremos

$4^{\circ}$ Sobre essa questão, Lyotard nos diz: "what is added to nature finalized aesthetically is, in short, the loss of its finality. Under the name of the Analytic of the Sublime, a denatured aesthetic, or, better, an aesthetic of denaturing, breaks the proper order of the natural esthetics and suspends the function it assumes in the project of unification." (LYOTARD, Jean-François. Lessons on the analytic of the sublime. Transl. Elizabeth Rottenberg. Stanford, Stanford University Press, 2004, p. 53).

${ }^{41}$ Id., p. IO5

${ }^{42}$ Lebrun dirá que é aí que Kant supera Hegel que, por não ter conseguido antever uma arte não representativa, teria postulado o fim da arte. (Cf. LEBRUN, Gérard. Kant e o fim da metafísica. Tradução de Carlos Alberto Ribeiro de Moura. São Paulo, Martins Fontes, 2002, p. 593).

43 Sobre o sublime como categoria estética indispensável à compreensão da arte contemporânea, ver: BARRETO, 1998. 
prioridade aqui à Teoria estética, pois, diferentemente do que encontramos na Minima moralia, nela a leitura adorniana de Freud torna-se muito mais nuançada, permitindo ao autor atribuir relevância à sublimação na constituição do teor de verdade das obras de arte. A sublimação aparece nessa obra em articulação com o conceito de sedimentação sócio-histórica, sobre o qual atua como via de projeção do inconsciente. Isso se dá pois o teor de verdade da obra, naquilo que ela particulariza do universal, ecoa a cultura de forma não literal e inadvertida. Ou seja, quando o artista produz uma obra, os feixes históricos que o atravessam cristalizam-se empiricamente, mas sem que ele intencione fazê-lo, ${ }^{44} \mathrm{em}$ outras palavras, de maneira inconsciente. Nas palavras de Adorno:

O momento histórico é constitutivo nas obras de arte; as obras autênticas são as que se entregam sem reservas ao conteúdo material histórico da sua época e sem a pretensão sobre ela. São a historiografia inconsciente de si mesma da sua época; o que não é o último factor da sua mediação relativamente ao conhecimento. É isso precisamente que as torna incomensuráveis ao historismo que, em vez de seguir o seu próprio conteúdo histórico, as reduz à história que lhes é exterior. ${ }^{45}$

Na sublimação, a mediação aparece então na atribuição de um papel ao inconsciente no fazer artístico, uma vez que é através dele que emerge algo da dimensão sócio-histórica na qual o próprio artista está inserido, atribuindo à arte aquele viés universal (coletivo) a que me referia anteriormente. Assim, a teoria psicanalítica consegue trazer à luz algo de extraestético na arte que supera sua empiria, seu elemento mediador, decifrando o caráter social que ela exprime. Dessa forma, "fornece as articulações de uma mediação concreta entre a estrutura das obras e a estrutura social”. ${ }^{46}$ No entanto, ao mesmo tempo em que atribui à sublimação

${ }^{44}$ Uma obra produzida com a intenção expressa de comunicar um momento histórico ou uma ideologia incorre na primazia do conteúdo sobre a forma, caracterizado por Adorno como obra de arte engajada, à qual ele tece duras críticas.

${ }^{45}$ ADORNO, Theodor W. Teoria estética. Tradução de Artur Morão. Lisboa, Ediçôes 70, 2016, p. 277.

${ }^{46}$ Id., p. 23 
um papel na canalização do sócio-histórico, Adorno destacará, de forma algo paradoxal, a importância do eco mítico do inconsciente, um vestígio daquilo de arcaico que habita em nós. Aqui, interessa-nos perceber como esse elemento mítico abala a vertente histórica do universal adorniano, conferindo-lhe uma fissura através da qual podemos vislumbrar um pano de fundo estático, necessário, inerente ao ser humano em qualquer tempo. Essa aparente contradição conceitual é, no entanto, essencial para escapar àquela aproximação historicista que já pontuei como inadequada à leitura adorniana: ao garantir o espaço do mítico, afasta-se o positivismo histórico.

Mas, se a natureza só pode, por assim dizer, ver-se de um modo cego, então a percepção e a lembrança inconscientes são esteticamente inalteráveis e constituem ao mesmo tempo rudimentos arcaicos, inconciliáveis com a crescente maioridade racional. ${ }^{47}$

Assim, a figura do inconsciente freudiano é essencial para Adorno, pois é exatamente a não-intencionalidade da consciência que permite que a sedimentação do conteúdo no construto estético ocorra de forma legitima, escapando à falsa reconciliação pela presença de seu momento mítico. Através dessa leitura dialética do universal advindo do inconsciente, é possível sustentar que a sublimação freudiana é um elemento chave no estabelecimento da obra de arte autêntica, ferramenta que permite que o universal nela se cristalize sem torná-la arte engajada, mera evidência de uma narrativa historicista artificial. ${ }^{48}$

\section{Do caráter utópico da arte}

Tanto a sublimação das pulsões, naquilo que elas apresentam de reconfortante para o sujeito, quanto a experiência do sublime, enquanto esta apresenta também um momento de prazer, trazem em si uma efêmera ilusão de reconciliação. Por ser um juízo reflexionante, o sublime passa pelo terror representado pela natureza

\footnotetext{
${ }^{47}$ Id., p. II2.

48 "A interacção do universal e do particular, que se produz inconscientemente nas obras de arte e que a estética tem de elevar à consciência, é a verdadeira necessidade de uma concepção dialéctica da arte.” (Id., p. 274).
} 
para desembocar em uma harmonização das faculdades, que restaura a unidade ameaçada do sujeito. De maneira análoga, a sublimação busca o consolo das pulsões através de uma realização externa que resgate o equilíbrio psíquico. No entanto, por manterem um elemento de respeito ${ }^{49}$ pelo desejo, conseguem, através da imaginação, afastar-se da ameaça de reificação do desejo. Em outras palavras, mais do que apagamento do desejo, ambos os processos privilegiam, de fato, um encontro com ele. São respostas a desejos já anunciados, que, por não encontrarem lugar no sujeito, suplicam à imaginação que desbrave uma via de alívio. Assim, a presença do desejo é a característica que une esses processos, através da clara enunciação da força exercida pela natureza (na figura do mundo administrado ou mesmo do princípio de realidade) que se contrapóe a ele. De fato, aquela ilusão de reconciliação que a arte pode oferecer é o elemento que a sociedade de controle tem por hábito instrumentalizar. Mas essa harmonização apaziguadora é ilusória frente à determinação da natureza, do mundo em desarmonia, que oprime o sujeito. E a arte não deixa de expressar, nesses termos, mesmo que de forma negativa, a consciência desse descompasso, dessa cisão. Como Adorno coloca, na Teoria estética: "No mundo falso, toda hedoné é falsa. Por conseguinte, o desejo sobrevive na arte". ${ }^{\circ}$

Essa linha interpretativa encontra respaldo em textos de Freud, por exemplo n'O futuro de uma ilusão, de 1927 , no qual ele pontua a falta de compromisso da ilusão com a realidade, o que garante que aquela figure como trincheira do desejo:

O que é característico das ilusões é o fato de derivarem de desejos humanos. (...) As ilusões não precisam ser necessariamente falsas, ou seja, irrealizáveis ou em contradição com a realidade. (...) Podemos, portanto, chamar uma crença de ilusão quando uma realização de desejo constitui fator proeminente em sua motivação e, assim

\footnotetext{
${ }^{49}$ Sobre o papel do "respeito" no sublime kantiano. (Ver LYOTARD, 2004, pp. 159-190.)

${ }^{\circ}$ ADORNO, Theodor W. Teoria estética. Tradução de Artur Morão. Lisboa, Edições 7o, 2016, p. 29.
} 
procedendo, desprezamos suas relações com a realidade, tal como $a$ própria ilusão não dá valor à verificaçãa.$^{51}$

A ilusão, da qual se serve a arte, implica uma dupla lucidez: ao mesmo tempo em que traz em si a aceitação da condição trágica da realidade, reitera a dimensão da imaginação (fantasia) como espaço privilegiado para o trato (e resguardo) do desejo. ${ }^{52}$ Fica, assim, preservada a promesse de bonheur. Pode-se argumentar que esse movimento só é possível graças à plasticidade das pulsóes que permite sua adequação, mesmo que parcial, ao princípio de realidade. Sobre a distensão do vínculo com a realidade, Freud dirá em $O$ mal-estar na civilização:

a satisfação é obtida através de ilusões, reconhecidas como tais, sem que se verifique permissão para que a discrepância entre elas e a realidade interfira na sua fruição. A região onde essas ilusões se originam éa vida da imaginação. (...) À frente das satisfaçóes obtidas através da fantasia ergue-se a fruição das obras de arte, fruição que, por intermédio do artista, é tornada acessível inclusive àqueles que não são criadores. ${ }^{53}$

Esse movimento pode ser caracterizado como uma disrupção da forma, um alargamento do objeto do desejo, o que nos remete ao sublime kantiano e seu ponto de partida sensível. É da necessidade de extrapolar a forma que advém o encontro com o campo da imaginação, que absorve o sensível negativamente. Sem o contraponto sensível, a imaginação não poderia se estabelecer como esfera do utópico. Para que a arte possa, conforme vislumbra Adorno, denunciar as incongruências da realidade e seu caráter contingente, ela precisa trazer em si algo deste mundo que pretende criticar. Sobre esse lastro do real, Lebrun pontua:

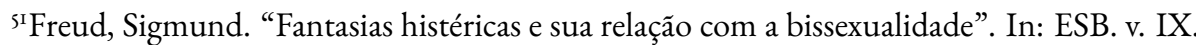
Rio de Janeiro, Imago, 1969, p. 44. (Grifo nosso.)

${ }^{52}$ Cf. MARTINS, Cecília Freire.Sublimação e idealização: destinos da pulsão na construção da cultura. Tese de doutorado - Programa de Pós-graduação em Psicologia da PUC-Rio. Rio de Janeiro, 2016, pp. 98-99.

${ }^{53}$ FREUD, Sigmund. O mal-estar na cultura. Tradução de Renato Zwick. Porto Alegre, L\&PM, 20I0, pp. 99-Ioo. (Grifo nosso.) 
"a presença do objeto no sublime permanece necessária como polo negativo de repulsão" ${ }^{44} \mathrm{O}$ conceito de expressão adorniano, por sua vez, ao mesmo tempo que insiste na relevância do momento extra-empírico na experiência estética, guarda a proeminência da imanência do construto, o que subentende uma flexibilização dessa forma peculiar de empiria que é a obra de arte. Para ele, é inerente ao fazer artístico a luta travada entre a consciência, alimentada pela ilusão, e o mundo, que oferece os limites, os parâmetros a serem dobrados. É através das imposições incontornáveis da realidade que o trabalho do artista é levado a adequar o desejo aos caminhos possíveis da matéria, tornando manifesta a dialética entre a impossibilidade de realização do desejo e sua parcial conservação empírica. $\mathrm{O}$ conflito do sujeito com a matéria deixa marcas de sonho, de desejo, juntamente com o registro de seu impedimento no mundo dito real; é na fantasia que o desejo encontra um lugar seguro para transfigurar-se em utopia. Assim, a obra de arte tomada como expressão parece assegurar aquilo que a estética do sublime kantiana e a sublimação freudiana traziam avant la lettre de essencial ao trato com a arte moderna e contemporânea: a primazia da imaginação.

${ }^{54}$ LEBRUN, 2004, p. 589. 


\section{Referências bibliográficas}

ADORNO, Theodor W. Minima moralia. Tradução de Artur Morão. Lisboa: Edições 70, 1993.

- Dialética negativa. Tradução de Marco Antônio Casanova. Rio de Janeiro: Jorge Zahar, 2009.

. Teoria estética. Tradução de Artur Morão. Lisboa: Ediçôes 70, 2016.

; HORKHEIMER, Max. Dialética do esclarecimento. Tradução de Guido Antonio de Almeida. Rio de Janeiro: Zahar, 2006.

BARRETO, Marco. "A imaginação e o sublime - herança de um pavor: de Kant a Bachelard”. In: DUARTE, Rodrigo (Org.) Belo, sublime e Kant. Belo Horizonte: UFMG, I998, pp. 173-I8I.

DUARTE, Rodrigo. "Sublimação ou expressão: um debate sobre arte e psicanálise a partir de T. W. Adorno”. In: Revista brasileira de psicanálise, v. 32 (2), 1998, pp. 319-335.

FABBRINI, Ricardo. “O fim das vanguardas”. In: Cadernos da pós-graduação. Instituto de Arte/Unicamp, ano 8, n. 2, pp. III-I29, 2006.

FREUD, Sigmund. "O escritor criativo e devaneios". In: "Gradiva" de Jensen e outros trabalhos (1906-1908). Disponível em: http: //conexoesclinicas.com.br/wp-content/uploads/2015/01/ freud-sigmund-obras-completas-imago-vol-09-1906-1908.pdf Acesso em: Io jul. 2019.

- A correspondência completa de Sigmund Freud para Wilhelm Fliess 1887-1904. Tradução de Vera Ribeiro. Rio de Janeiro: Imago, 1986.

. "Fantasias histéricas e sua relação com a bissexualidade”. In: ESB. v. IX. Rio de Janeiro: Imago, 1969.

. "Fragmentos da análise de um caso de histeria”. In: ESB. v. VII. Rio de Janeiro: Imago, 1969b.

. O mal-estar na cultura. Tradução de Renato Zwick. Porto Alegre: L\&PM, 2оIо.

GARCIA, C. A. "Sublimação e cultura de consumo". In: RABELLO DE CASTRO, Lucia. (Org.) Infância e adolescência na cultura do consumo. Rio de Janeiro: NAU, 1998. 
KANT, Immanuel. Critica da faculdade de julgar. Tradução de Daniela Botelho B. Guedes. São Paulo: Ícone, 2009.

LEBRUN, Gérard. Kant e o fim da metafísica. Tradução de Carlos Alberto Ribeiro de Moura. São Paulo: Martins Fontes, 2002.

LOFFREDO, Ana Maria. Figuras da sublimação na metapsicologia freudiana. São Paulo: Escuta/Fapesp, 2014.

LYOTARD, Jean-François. Lessons on the analytic of the sublime. Transl. Elizabeth Rottenberg. Stanford: Stanford University Press, 2004.

MANDIL, Ram Avran. Entre ética e estética freudianas: a função do belo e do sublime n'A estética da psicanálise" de J. Lacan. Dissertação de mestrado. Orientação de Rodrigo Duarte. Belo Horizonte: UFMG, 1993.

MARCUSE, Herbert. Eros e civilização. Uma interpretação filosófica do pensamento de Freud. Tradução de Álvaro Cabral. Rio de Janeiro: Zahar, 1975.

MARTINS, Cecília Freire. Sublimação e idealização: destinos da pulsão na construção da cultura. Tese de doutorado - Programa de Pós-graduação em Psicologia da PUC-Rio. Rio de Janeiro, 2016.

Resumo: O presente trabalho pretende investigar a teoria estética adorniana, naquilo que ela apresenta sobre a relação entre arte e sociedade, buscando aproximações com os conceitos de sublime kantiano e sublimação freudiana. Elucidar, primeiramente, como o caráter emancipatório da obra de arte depende de sua não subserviência à realidade, analisando, por esse viés, as consonâncias e contradiçốes com a sublimação freudiana, enquanto adequação social, e com estética kantiana,
AbSTRACT: The present work intents to investigate Adorno's aesthetic theory in regards to the relation between art and society, searching for points of convergence with the concepts of sublime in Kant and of sublimation in Freud. It aims to bring to light, at first, how the emancipatory aspect of the work of art depends on its non-subservience to reality, clarifying possible consonances and discrepancies with Freudian sublimation (understood as social adequacy) and with 
particularmente na premissa de idonei- Kantian aesthetics (specially in its exdade da natureza. Em seguida, quanto pectations of nature idoneity). Thereafao caráter sócio-histórico da arte, in- ter, in regards to the socio-historical asvestigar aquilo que a arte apresenta de pect of art, investigate what art presents extra-artístico na constituição do teor as extra-aesthetic in the development of de verdade das obras, articulando a se- the works' truth content, articulating dimentação adorniana e os momentos Adorno's sedimentation and the mediamediados da experiência estética em ted moments of aesthetic experience in Freud e Kant. Por fim, procura-se mos- Kant and Freud. At last, demonstrate trar como a vertente utópica da arte, how the utopian dimension of art as conforme apresentada por Adorno, de- Adorno presents it depends on premipende de premissas encontradas em ses found in Freud and Kant, explicit Freud e Kant, manifestas na primazia in the primacy of imagination.. da imaginação.

KEYwORDs: Adorno; expression;

Palavras-chave: Adorno; ex- sublime; sublimation; art and society. pressão; sublime; sublimação; arte e sociedade. 